\title{
Importance of Theory in Learning Analytics in Formal and Workplace Settings
}

\author{
Shane Dawson, Negin Mirriahi, and Dragan Gašević \\ Editors, Journal of Learning Analytics \\ jla.editorial@gmail.com
}

\begin{abstract}
This issue is a call for researchers and practitioners to reflect on progress to date and understand the criticality of theory - how it facilitates interpretation of findings but also how it can also restrict and confine our thinking through the assumptions many theoretical models bring. As education paradigms further shift and juxtapose informal and formal learning settings there is a need to re-visit any underlying theoretical assumptions.
\end{abstract}

\section{THEORY AND LEARNING ANALYTICS}

There has been much written over the past few years regarding the potential of learning analytics to transform education practice. The rationale is well argued as new forms of naturally occurring learning data become increasingly available prompting new approaches to education research. The ready access to large stores of student ICT interaction data continues to fuel the growth of the field. This growth and expansion is well evidenced in the unprecedented volume of papers submitted to the most recent 2016 Learning Analytics and Knowledge conference. We are also witnessing an increase in the number of special issues devoted to research in the field as journals stretch their methodological scope to investigate how new and alternate analytic approaches can provide novel insights into learning and teaching. However, the rapid promotion and adoption of more and more quantitative methods derived from student driven ICT data and crude assessment scores may result in unanticipated and deleterious learning outcomes.

While we are very much advocates for what believe the advances such analytics will bring to the education field, we must also take stock and review our progress, assumptions and the limitations of our research. Analytics is at present in a space where research is rapidly outpacing current practice and broad scale sector understanding of how such information can be applied in education. This concern is further compounded when considering the proliferation of analytics tools touted as institutional solutions to complex problems such as attrition, diminishing academic performance and establishing rigorous personalized learning models. A recent Australian higher education benchmarking initiative highlights these concerns and the complexities involved in the implementation of learning analytics (Colvin et al., 2015). The national study revealed that, while learning analytics was a much-noted strategic priority for all Australian Universities, very few were able to implement or even launch a whole 
(2015). Importance of theory in learning analytics in formal and workplace settings. Journal of Learning Analytics, 2(2), 1-4. http://dx.doi.org/10.18608/jla.2015.22.1

of institution learning analytics project. The report attempts to unpack why learning analytics implementations are predominantly stalled or non-existent. Here, the authors argued that the models and frameworks guiding adoption strategies fail to account for the complexity of learning analytics implementations and lack an empirical grounding in their development. As such there is a critical absence for empirical research informing the development of these frameworks and how such research can lead to new theoretical understandings. Yet this is only one side of the coin - essential to this work is the complementary view of how theory can inform applied research. Gašević and colleagues (2016) also make this point in noting that the empirical research undertaken to date, have not sufficiently considered or taken account of learning theory.

This issue is a call for researchers and practitioners to reflect on progress to date and understand the criticality of theory - how it facilitates interpretation of findings but also how it can also restrict and confine our thinking through the assumptions many theoretical models bring. As education models further shift and juxtapose informal and formal learning settings there is a constant imperative to revisit the legitimacy of any underlying theoretical assumptions. Essentially, many applied theories were formed in an education context that bears minimal resemblance to contemporary education practice. The notion of higher education, as a simple four year program of study designed to develop critical thinking, disciplinary knowledge and argumentation and equip graduates with the necessary foundational skills to transition into a lifetime of future employability, has well and truly expired.

\section{LEARNING ANALYTICS IN THE WORKPLACE}

Although learning analytics has received much research attention, the current focus has been on formal education settings. The recent manifesto for learning analytics in the workplace produced by the LACE project ${ }^{1}$ stresses the need for lifelong learning and how analytics can facilitate workforce training (Cardinali et al., 2015). Similar to how learning analytics has the potential to personalize learning experiences, inform teaching practice, and provide opportunities for evidence-based student interventions, the advances in digital technologies adopted in the workforce and industry can facilitate and enhance workplace learning. As the LACE manifesto states:

"blending analytics and learning innovation to conceive and implement new working environments capable to constantly analyse, diagnose, and support the performance of users, and offer them context-aware and intelligent learning experiences directly at the workplace, in their day-to-day workflow, is going to be crucial for the workforce of the future" (Cardinali et al., 2015, p. 8).

Professional development and workplace learning opportunities are beginning to offer targeted just-intime resources and educational experiences to support workers development of skills and knowledge required for a rapidly progressing technological society. Leveraging the trace data from workers' use of and engagement with digital technologies coupled with their intentions or goals for upskilling or

\footnotetext{
${ }^{1}$ http://www.laceproject.eu/
} 
(2015). Importance of theory in learning analytics in formal and workplace settings. Journal of Learning Analytics, 2(2), 1-4. http://dx.doi.org/10.18608/jla.2015.22.1

developing their knowledge, provides an exciting opportunity to deliver nuanced personalized resources and guide workers on their own professional learning journeys.

However, do the learner motivations, instructional practices and approaches that guide learning in the workplace lend themselves to the same theoretical assumptions in formal learning environments? Particularly, when upskilling and lifelong learning in the workforce may not necessarily lead to formal qualifications or where extrinsic motivations are constrained or limited? Further, the just-in-time learning that often occurs in the workplace is considerably different from the formal semesters or cohort-based learning environments where learning communities of students can be cultivated providing opportunities for social and collaborative learning and the development of trusted engagement with one another and the teacher critical for digital or online learning in particular. On the other hand, workplace learning is contextually embedded into the workplace tasks and most commonly occurs through informal opportunities. Short, although timely, learning and training in the workplace often meets such challenges and further research is needed to better understand how and why the needs of workplace learners differ from formal students, particularly in digital learning environments. Such understanding will help to theoretically guide the development of workplace learning opportunities reflective of the needs of a knowledge economy.

\section{IN THIS ISSUE}

The papers in this issue raise numerous critical questions for the field of learning analytics - what counts as meaningful data; how can theory inform direct action; are algorithms transportable across context and are oft utilized educational theories still relevant in a changing learning paradigm? In the present issue Special Section Editors - Wise and Schaeffer attempt to tackle these very pertinent and timely concerns and challenges. The collection of papers addresses the importance of building a more theoretically driven approach to learning analytics research. The special section is also significant in that it shows the commitment of the Journal of Learning Analytics to experiment with innovative models of publications. For a healthy development of the new field, we need to create and facilitate a forum where researchers can engage in an open debate about the value of different methods and theoretical underpinnings in their learning analytics inquiry. Wise and Schaeffer decided to stimulate this debate through the inclusion of commentaries on each paper accepted in their special section. These commentaries, written by the reviewers of the accepted papers, offer a critical perspective on relevant issues that need to be pursued in future research. We would like to stress that we would welcome proposals of prospective guest editors of new special sections who are interested in developing innovative publication models that can additionally promote the development of the field of learning analytics.

This issue also contains one regular research paper. Lowes, Lin, and Kinghorn (this issue) take a different perspective from the special section and do not focus on the link between learning analytics and learning theory. Rather, Lowes and the colleagues explore the association between online behaviours 
(2015). Importance of theory in learning analytics in formal and workplace settings. Journal of Learning Analytics, 2(2), 1-4. http://dx.doi.org/10.18608/jla.2015.22.1

and course performance in asynchronous online high school courses. They report on the findings of a study that analyzed trace data from a learning management system used by 800 students enrolled in 12 online courses. The findings of this study reveal patterns in the association between students' online activity and academic success and show that gender needs to be accounted for when conducting analyses with trace data recorded by learning management systems.

\section{EDITORIAL TEAM UPDATE}

We would like to introduce and welcome Jelena Jovanović to the editorial team. Jelena will be an editor of the Host Spots practitioner section of the journal. Jelena brings years of experience in learning analytics. She is probably one of the first individuals to complete her PhD in learning analytics in 2007. She also is the main developer of one of the first learning analytics tools - LOCO-Analyst - that aimed to empower instructors through feedback provision about activities of their students in online learning environments. We are very excited to have Jelena on board and look forward to collaborating with her. If you have any ideas for papers in the Hot Spots section of the journal, you are welcome to drop a note to Jelena.

\section{REFERENCES}

Cardinali, F., Chazerand, P., Flocken, S., Glaser, J., Kismihok, G., Mateum, J., ... Vanarwegen, M. (2015). The LACE LAW Manifesto, Learning Analytics Review no. 4. Retrieved from http://www.laceproject.eu/learning-analytics-review/LACE-LAW-manifesto/

Colvin, C., Rogers, T., Wade, A., Dawson, S., Gašević, D., Buckingham Shum, S., ... Fisher, J. (2015). Student retention and learning analytics: A snapshot of Australian practices and a framework for advancement (Research Report). Canberra, Australia: Office of Learning and Teaching, Australian Government.

Gašević, D., Dawson, S., Rogers, T., \& Gasevic, D. (2016). Learning analytics should not promote one size fits all: The effects of instructional conditions in predicting learning success. The Internet and Higher Education, 28, 68-84. http://dx.doi.org/10.1016/j.iheduc.2015.10.002 